\title{
PERCEPÇÃO DOS EMPRESÁRIOS DE MICRO E PEQUENAS EMPRESAS SOBRE O USO DO PLANEJAMENTO ORÇAMENTÁRIO COMO FERRAMENTA DE AUXÍLIO À GESTÃO
}

\author{
PERCEPTION OF ENTREPRENEURS OF MICRO AND SMALL COMPANIES \\ REGARDING THE USE OF BUDGETARY PLANNING AS MANAGERIAL TOOL
}

\author{
Leonardo Flach \\ Universidade Federal de Santa Catarina - UFSC \\ E-mail: leonardo.flach@gmail.com \\ Luísa Karam de Mattos \\ Universidade Federal de Santa Catarina - UFSC \\ E-mail: luisakmattos@gmail.com
}

\section{RESUMO}

Esta pesquisa tem por objetivo analisar a percepção de empresários de micro e pequenas empresas sobre os instrumentos de planejamento orçamentário utilizados para a gestão de suas empresas. A pesquisa classifica-se como descritiva e quantitativa. Visa contribuir no controle de gestão da microempresa ao utilizar o planejamento orçamentário para a tomada de decisão e analisar as projeções geradas a fim de propor um método de análise dos resultados esperados. A coleta de dados ocorreu por meio de entrevistas realizadas com gestores de micro e pequenas empresas. Para tratamento dos dados utilizou-se a análise descritiva e inferência estatística. Os resultados desta pesquisa ajudam a evidenciar o uso do planejamento orçamentário como um instrumento usado para o processo de gestão nas micro e pequenas empresas.

Palavras-chave: Planejamento Orçamentário; Microempresa; Controladoria; Orçamento.

\begin{abstract}
This research aims to analyze the perception of entrepreneurs of micro and small companies about the budgetary planning instruments applied for the management of their companies. The research is descriptive and quantitative. The results contribute to microenterprise management control by using the budget planning for decision making and analyzing the projections, in order to propose a method to analyze the expected results. Data collection was through interviews with managers of micro and small companies. For the data treatment, we applied descriptive analysis and statistical inference. The results of this research help to highlight the use of budget planning as an instrument used for the management process in micro and small enterprises.
\end{abstract}

Keywords: Budget Planning; Micro Enterprise; Controller; Budget. 


\section{INTRODUÇÃO}

No Brasil, vem crescendo a cada dia o número de empreendimentos formais e informais. Conforme estudo realizada pelo grupo de redes de negócios do Reino Unido, Approved Index, o Brasil encontra-se na terceira colocação dentre os países mais empreendedores do mundo (Brinded, 2015).

O número de Microempreendedores individuais (MEI) de micro e pequenas empresas (MPE) está crescendo ao longo dos anos, e está contribuindo para o avanço da economia no país. Sua atuação, que era de $21 \%$ no ano de 1985, apresentou um aumento. No ano de 2011 passou a ser de $27 \%$. Essa ascensão ocorreu mais nos setores de comércio e serviço (Sebrae, 2019). Neste sentido, torna-se importante saber se os gestores de micro e pequenas empresas estão utilizando instrumentos de planejamento orçamentário.

As empresas têm como objetivo, desde a sua constituição, o crescimento e o retorno financeiro, através da prestação de serviços ou venda de mercadorias. Para que a empresa seja considerada atrativa no mercado globalizado, tanto para o consumidor como para os investidores, devem melhorar seus serviços e/ou produtos, seus processos financeiros e/ou administrativos, que são realizados de forma conjunta com um planejamento e controle orçamentário.

O planejamento, independentemente do porte da empresa, é uma ferramenta importante para a tomada de decisão. Ela é essencial para a sobrevivência da empresa e seu sucesso está intimamente ligado a um bom planejamento. Essa discussão é de interesse das MPE, afinal, são o grupo com a maior taxa de mortalidade no Brasil, conforme apresentado na pesquisa feita pelo Serviço Brasileiro de Apoio às Micro e Pequenas Empresas (Sebrae, 2016).

A falta de planejamento nas pequenas empresas, muitas vezes impacta diretamente no orçamento da empresa, o que tem a ver com a carência de conhecimento e tempo do empresário para exercer e analisar essas atividades gerenciais (Resnik,1990; Pontes, 2013)

Segundo, Lopes e Blaschek (2005, p. 1) "o processo orçamentário é o elemento principal do controle gerencial na maior parte das organizações, possuam elas fins lucrativos ou não". Frezatti $(2009$, p. 47) afirma que "o orçamento surge como sequência à montagem do plano estratégico, permitindo focar e identificar [...] suas ações mais importantes". O autor também ressalta que o orçamento existe para auxiliar na execução das decisões do plano estratégico.

Resnik (1990) comenta que os enfoques das pequenas empresas são para as atividades imediatas e que veem o planejamento de forma teórica. Seguindo a ideia, o autor afirma que onde o planejamento não está presente, tanto as pessoas quanto as empresas perecem.

Deste modo, a pergunta que orienta esta pesquisa é: qual é a percepção de empresários de micro e pequenas empresas sobre os instrumentos de planejamento orçamentário utilizados para a gestão de suas empresas? Diante do problema apresentado, a pesquisa tem como objetivo geral objetivo analisar a percepção de empresários de micro e pequenas empresas sobre os instrumentos de planejamento orçamentário utilizados para a gestão de suas empresas.

Tem-se como justificativa desta pesquisa a importância do planejamento e controle nas pequenas empresas, visto que elas vêm ganhando cada vez mais espaço no mercado. As micro e pequenas empresas vêm crescendo ao longo dos anos contribuindo para o avanço do país. No setor de comércio, elas representam um total de 53,4\% do Produto Interno Bruto (PIB) brasileiro. 


\section{REVISÃO DA LITERATURA}

Neste tópico são apresentadas as discussões teóricas que embasaram o objetivo do estudo, referentes ao planejamento orçamentário em micro e pequenas empresas.

\subsection{Planejamento orçamentário}

O orçamento é um instrumento que auxilia as empresas a definir um plano a ser desenvolvido na procura de melhorar os seus recursos, de maneira que possam ser gerenciados, a fim de subsidiar a sua tomada de decisão (Padoveze, 2006; Frezatti, 2009).

Oliveira (2010, p.5) definiu o planejamento "como o desenvolvimento de processos, técnicas e atitudes administrativas, as quais proporcionam [...] avaliar as implicações futuras de decisões presentes em função dos objetivos empresarias que facilitarão a tomada de decisão no futuro".

Sob essa perspectiva, o planejamento é a parte principal das atividades gerencias, sendo a primeira etapa do processo de qualquer projeto a ser desenvolvido pela empresa, direcionando a tomada de decisão no longo ou no curto prazo (Pontes, 2013; Padoveze, 2009) Fank, Angonese e Lavarda (2011) comentam que é a partir do plano orçamentário que se pode confirmar se serão atingidas as metas propostas no planejamento.

O orçamento é uma ferramenta importante para a tomada de decisão, isso "ocorrerá sempre que algum padrão montado a partir da missão, dos objetivos e das metas empresariais possa ser organizado partindo de um programa orçamentário, capaz de criar padrões econômicos que projetem, para o futuro, o resultado operacional das empresas" (Fernandes, 2005, p. 17).

Orçamento, para Frezatti (2009, p.46), é “o plano financeiro para implementar a estratégia da empresa para determinado exercício". Já Padoveze (2015, p. 31) afirma que é "a ferramenta de controle por excelência de todo o processo operacional da empresa, pois envolve todos os seus setores". O orçamento pode ser desenvolvido de diversas maneiras, dependendo do tipo e do porte da organização. Neste sentido, Padoveze (2015, p. 43), conclui que "não existe uma única maneira de estruturar o orçamento e, consequentemente, de fazer o processo de avaliação e controle".

Segundo Correia Neto (2011, p. 15) "o orçamento tem duas funções distintas, indissociáveis e complementares: planejamento e controle [...] e o simples fato da ocorrência de uma sugere a ocorrência da outra".

As funções do orçamento na organização são entendidas quando associadas às funções administrativas (Oliveira, Perez \& Silva, 2009). De acordo com o autor, as funções podem ser descritas de três formas: planejamento, execução e controle (Oliveira et al., 2009). As metas e objetivos são as funções básicas do orçamento. Catelli (2001, p. 250) afirma que as "funções dos orçamentos consiste na coordenação dos esforços que serão desenvolvidos pelas diversas áreas e gestores da empresa para o atingimento de seus objetivos da empresa em sua totalidade".

Segundo Padoveze (2010, p.530), a estrutura do orçamento pode ser dividida em 3 partes: orçamento operacional; orçamento de investimentos e financiamentos; projeção dos demonstrativos contábeis. Sobre os orçamentos operacionais, Frezatti (2009, p. 54) destaca que "proporcionam condições de estruturação das atividades da organização, de maneira a integrar as atividades, as operações". De acordo com o autor, o orçamento de investimentos e financiamentos trata da "tradução de todas as atividades para uma mesma linguagem comum, no caso a monetária” (Frezatti, 2009, p.54). 
A projeção dos demonstrativos contábeis consolida todos os orçamentos. Como parte do balanço patrimonial inicial, ela "incorpora o orçamento operacional e o orçamento de investimentos e financiamentos, projeta as demais contas e conclui com um balanço patrimonial final" (Padoveze, 2010, p. 531).

Na Figura 1 é apresentado um esquema geral do plano orçamentário, para melhor visualização da estrutura do orçamento, levando-se em consideração as suas peças principais.

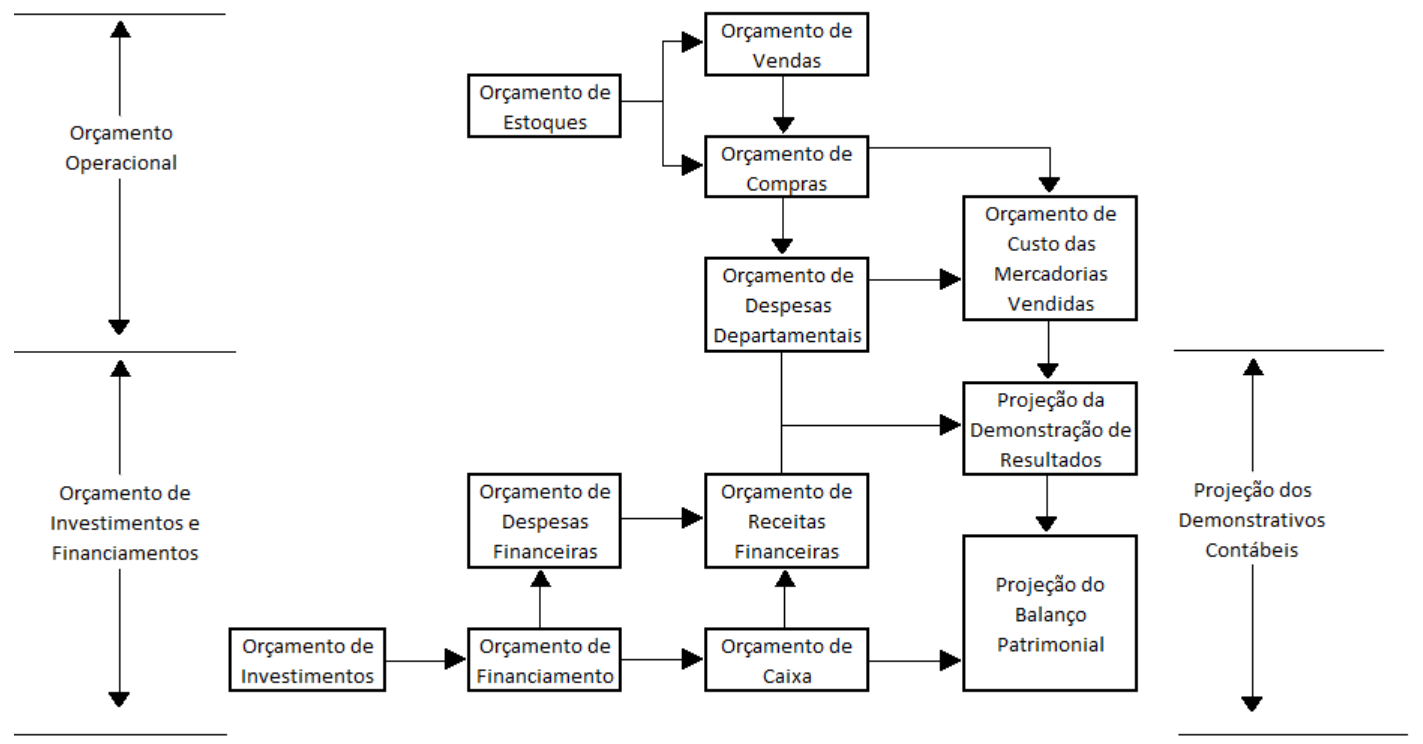

Figura 1. Esquema geral do plano orçamentário

Fonte: Padoveze (2010, p.532)

O plano orçamentário é elaborado a partir das projeções financeiras de cada unidade da empresa, onde englobam as decisões operacionais e financeiras. Conforme Lunkes (2010, p.37) "as decisões operacionais visam a aquisição e uso de recursos escassos, enquanto as decisões financeiras concentram-se em obter os meios para adquiri-los".

O orçamento operacional é o primeiro orçamento a ser feito. "Trata-se do orçamento das receitas, que parte da previsão de vendas e da previsão dos preços dos produtos e serviços a serem vendidos" (Padoveze \& Taranto, 2009, p.27). Logo em seguida, vem o orçamento de investimentos e financiamentos. "O enfoque básico é elaborar o orçamento dos gastos previstos com investimentos que serão ativados como ativo permanente, bem como dos financiamentos necessários para fazer face à necessidade de fundos para sua aquisição" (Padoveze, 2010, p.557).

A última parte do plano orçamentário é a das projeções, que são "todas as receitas e as despesas geradas em cada peça orçamentária são reunidas para projetar o resultado" (Padoveze \& Taranto, 2009, p.51).

Segundo Lunkes (2010), o orçamento empresarial foi o que prevaleceu na primeira fase do orçamento. De acordo com o autor, o orçamento empresarial é "um plano projetado para atender a um nível de atividade do próximo período" (Lunkes, 2010, p.38).

$\mathrm{O}$ orçamento contínuo foi o que predominou na segunda fase do orçamento, que tem como destaque "a revisão contínua, removendo-se os dados do mês recém-concluída e acrescentando-se dados orçados para o mesmo mês do ano seguinte" (Lunkes, 2010, p.38). Para Padoveze e Taranto (2009, p.36), "o fundamento primordial desse conceito, chamado de rolling budget, concentra-se no período em que o orçamento ou a projeção será realizado".

Em seguida vem a terceira fase, o orçamento de base zero (OBZ). "As empresas que adotam o conceito de OBZ discutem anualmente, na época da elaboração do orçamento, cada 
uma de suas atividades, considerando a necessidade ou não de sua existência" (Padoveze \& Taranto, 2009, p. 38).

O orçamento flexível "é projetado para cobrir uma uma gama de atividades, portanto, pode ser usado para estimar custos a qualquer nível de atividade" (Lunkes, 2010, p. 38). Essa é a quarta fase da evolução dos processos orçamentários.

Em seguida, o orçamento por atividades nasceu como uma continuação do custeio baseado por atividades, com o uso de direcionadores de custos para avaliar e controlar a carga de recursos (Lunkes, 2010).

Por fim, o beyond budgeting "utiliza meios mais relativos e adaptáveis de planejamento, avaliação e controle de desempenho" (Lunkes, 2010, p.38). Segundo Frangiotti (2010, p.32), o beyond budgeting "surge como uma solução de gestão mais apta a esta dinâmica do mercado em detrimento do modelo tradicional e estático de orçamento".

Com a discussão apresentada sobre o planejamento orçamentário, as duas próximas fases também são tão importantes quanto a primeira. A segunda fase é a da execução, é a parte de avaliação e de colocar em prática os objetivos estipulados no planejamento. A última e não menos importante é a fase de controle, quando se observa as análises das etapas e avaliação do papel do orçamento (Suave, 2013; Pontes, 2013).

\subsection{Micro e pequenas empresas}

Atualmente, as MPEs representam a maioria das empresas brasileiras. Segundo estudo realizado pelo SEBRAE (2006), "elas representam 99\% do total das empresas do país, 28\% do faturamento do setor privado, $20 \%$ do PIB brasileiro e $2 \%$ do valor das exportações brasileiras". Com isso, as MPEs são grandes geradoras de empregos e auxiliam no crescimento do país.

Apesar do Brasil ter um grande número de MPEs, a classificação do porte da empresa, ainda não é padronizada. Isso acontece em decorrência "do fato de que a finalidade e os objetivos das instituições que promovem seu enquadramento são distintos" (IBGE, 2003). Na Tabela 1 está simplificada a classificação de MEI, ME e EPP.

Umas das principais deficiências das MPEs é a falta de planejamento, recursos financeiros e, principalmente, de controle. E devido à falta de estrutura que permita delegar e especializar atividades, o pequeno empresário tende a centralizar as atividades e acumular várias funções.

Tabela 1

Classificação de MPE no Brasil

\begin{tabular}{|c|c|c|}
\hline \multirow{2}{*}{ Instituição/ Porte } & \multicolumn{2}{|c|}{ Atividade Econômica } \\
\hline & Indústria & Comércio/Serviços \\
\hline SEBRAE & \multicolumn{2}{|c|}{ Número de pessoas ocupadas } \\
\hline Microempreendedor Individual - MEI & \multicolumn{2}{|c|}{$0-1$} \\
\hline Microempresa - ME & $0-19$ & $0-9$ \\
\hline Empresas de Pequeno Porte - EPP & $20-99$ & $10-49$ \\
\hline Lei Geral & \multicolumn{2}{|c|}{ Valor da Receita bruta } \\
\hline Microempreendedor Individual - MEI & \multicolumn{2}{|c|}{ Até 60.000 mil reais } \\
\hline Microempresa - ME & \multicolumn{2}{|c|}{$\leq 360.000,00$} \\
\hline Empresas de Pequeno Porte - EPP & \multicolumn{2}{|c|}{$>360.000,00 \mathrm{e} \leq 3.600 .000,00$} \\
\hline
\end{tabular}


Segundo o Ibge (2019), as características das MPEs são: baixa intensidade de capital; altas taxas de natalidade e de mortalidade: demografia elevada; forte presença de proprietários, sócios e membros da família; poder decisório centralizado; registros contábeis pouco adequados; contratação direta de mão-de-obra; utilização de mão-de-obra não qualificada ou semiqualificada; baixo investimento em inovação tecnológica; maior dificuldade de acesso ao financiamento de capital de giro; relação de complementaridade e subordinação com as empresas de grande porte.

A taxa de sobrevivência (Figura 2) das empresas com até 2 anos de atividade foi de $76,6 \%$, "essa taxa foi a maior taxa de sobrevivência de empresas com até 2 anos, já calculada para as empresas nascidas em todo o período compreendido entre 2008 e 2012" (Sebrae, 2019).

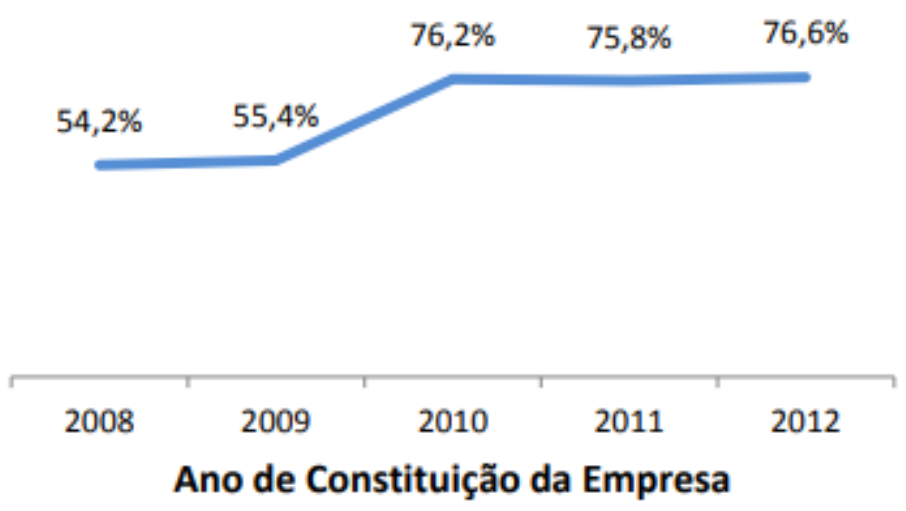

Figura 2. Taxa de Sobrevivência de empresas de 2 anos.

Fonte: dados do Sebrae (2019).

Referente a taxa de mortalidade (Figura 3) das empresas de até 2 anos, nota-se que caiu para 23,4\% no ano de 2012. "As empresas criadas no período entre 2008 e 2012 se beneficiaram de uma série de aspectos positivos, presentes no conjunto do período compreendido entre 2008 e 2014, o que ajuda a explicar o aumento da taxa de sobrevivência das empresas nesse período" (SEBRAE, 2016).

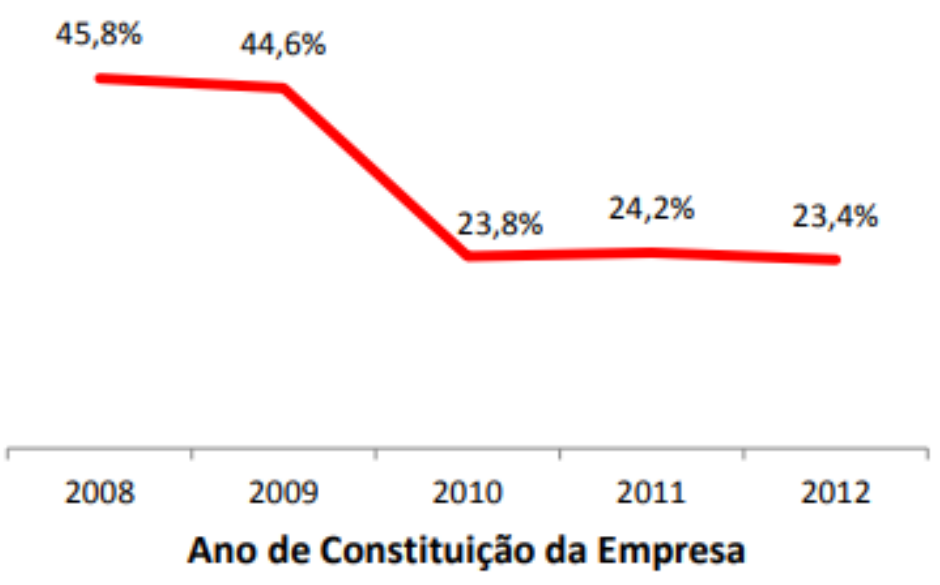

Figura 3. Taxa de Mortalidade de empresas de 2 anos Fonte: dados do Sebrae (2019). 
Conforme comenta Resnik (1990), a causa decisória para o sucesso e sobrevivência de uma empresa é a boa administração. A causa do fracasso é da má administração e não só dos fatores variáveis. $\mathrm{O}$ autor afirma que a boa administração de uma empresa "é mais do que o agrupamento das atividades diárias do proprietário, [...] ela também inclui as atitudes, percepções, pensamentos e conhecimentos [...] que motivam e governam suas atividades vitais" (Resnik, 1990 p. 4).

\section{MÉTODO DE PESQUISA}

Esta pesquisa é classificada como descritiva. Segundo Gil (2002, p. 42), “as pesquisas descritivas têm como objetivo primordial a descrição das características de determinada população ou fenômeno ou, então, o estabelecimento de relações entre variáveis".

O problema de pesquisa usa uma abordagem quantitativa. Richardson (2009, p. 70) afirma que "caracteriza-se pelo emprego da quantificação tanto na modalidade de coleta de informações, quanto no tratamento delas por meio de técnicas estatísticas."

A população utilizada para a pesquisa foram os empreendedores que participaram do evento oferecido pelo Sebrae, na cidade de Santos, no estado de São Paulo. Os participantes foram escolhidos de forma aleatória. Ao todo, foram entrevistados 32 empresários de micro e pequenas empresas.

Os dados da pesquisa foram coletados por meio de aplicação de questionários junto aos empreendedores, com o objetivo de conseguir informações se as empresas utilizam o orçamento empresarial como instrumento de auxílio ao processo de gestão organizacional.

Os dados coletados foram organizados através da planilha eletrônica Excel, elaborando em seguida gráficos e planilhas que correspondem à estatística descritiva.

\section{ANÁLISE E INTERPRETAÇÃO DOS RESULTADOS}

Dos empreendedores que estavam no evento, obteve-se respostas de 32. Do total, 11 empresas utilizam planejamento com horizonte de curto prazo, o que representa $52,4 \%$ da amostra, 10 deles, ou seja 47,6\% fazem uso do planejamento de longo prazo. Os empreendedores que estão com as suas empresas a mais de 10 anos no mercado representam $30 \%$ do total da pesquisa.

Os $65,6 \%$ dos empreendedores que utilizam o orçamento, somente 28,6 das empresas revisam suas metas mensalmente, $38,1 \%$ que foi a grande maioria, revisam suas metas semestralmente e apenas $9,5 \%$ revisam anualmente.

Outra pergunta que estava no questionário, é que se as estratégias da empresa são passadas para todos os colaboradores, $51,7 \%$ da amostra responderam que não e apenas $24,1 \%$ responderam que sim.

\subsection{Elaboração e utilização do orçamento empresarial}

O orçamento é utilizado por $65,6 \%$ das micro e pequenas empresas, das quais $90,5 \%$ utilizam como base o orçamento de receita, $33,3 \%$ no fluxo de caixa e apenas $28,6 \%$ nos de custos para determinar as projeções do orçamento.

Conforme o que mostra na Figura 4, observa-se que as projeções mais realizadas pelas empresas se referem aos orçamentos de vendas e projeção da DRE com $81 \%$, em seguida o orçamento de despesas com $52,4 \%$. 


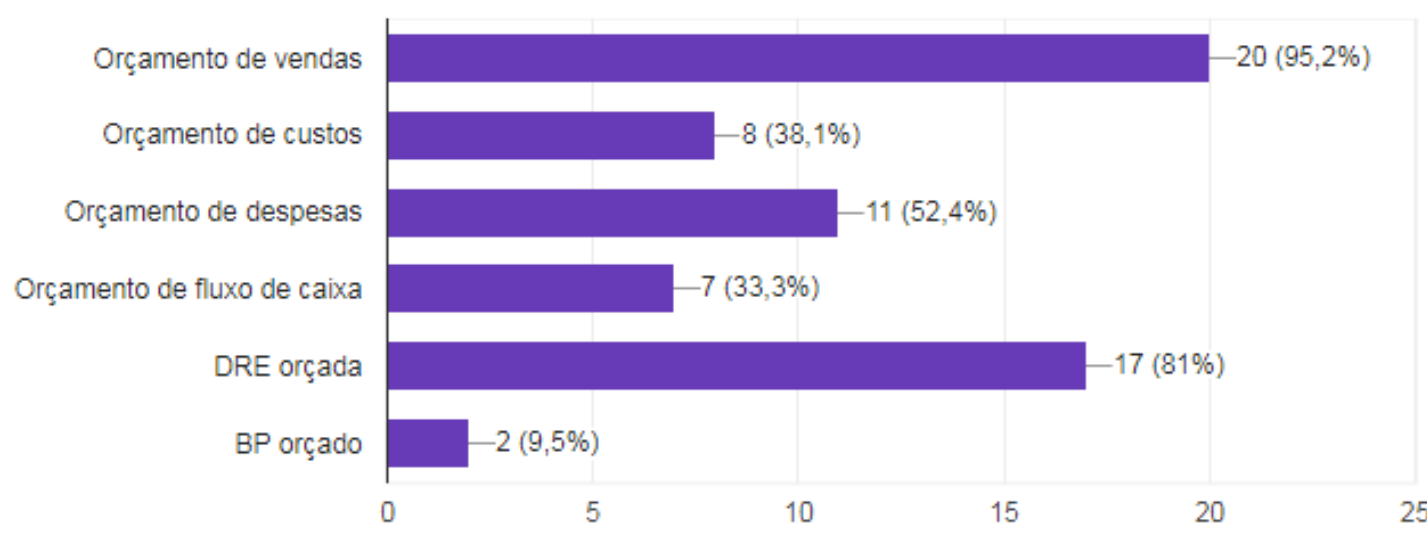

Figura 4 - Tipos de Projeções elaboradas pela empresa Fonte: Elaboração própria.

Os principais objetivos dos empreendedores, no momento de realizar as projeções, estão totalmente voltados para quanto pretendem vender durante determinado período e quanto se vai ter de lucro, demonstrando que tanto as receitas como a DRE possuem uma atenção especial quanto às decisões futuras.

A fim de identificar as principais causas pelos quais os empreendedores não utilizam o orçamento utilizou-se da escala Likert para definir o grau de relevância das características citadas, cujos resultados estão descritos na Tabela 2.

Tabela 2

Razões para não utilização do orçamento empresarial (em\%)

\begin{tabular}{l|c|c|c|c|c}
\hline & $\begin{array}{c}\text { Não concordo } \\
\text { plenamente }\end{array}$ & $\begin{array}{c}\text { Não concordo } \\
\text { parcialmente }\end{array}$ & Indiferente & $\begin{array}{c}\text { Concordo } \\
\text { parcialmente }\end{array}$ & $\begin{array}{c}\text { Concordo } \\
\text { plenamente }\end{array}$ \\
\hline Custo maior que benefício & 18,75 & 12,50 & 31,00 & 25,00 & 12,75 \\
\hline $\begin{array}{l}\text { Falta de conhecimento } \\
\text { sobre como se elabora }\end{array}$ & 25,00 & 9,38 & 6,25 & 40,63 & 18,74 \\
\hline $\begin{array}{l}\text { Dificuldades para sua } \\
\text { implantação }\end{array}$ & 21,88 & 12,50 & 3,13 & 15,63 & 46,86 \\
\hline $\begin{array}{l}\text { Não gera informações } \\
\text { importantes para a empresa }\end{array}$ & 31,24 & 9,38 & 25,00 & 21,88 & 12,50 \\
\hline $\begin{array}{l}\text { Não melhora o } \\
\text { desenvolvimento da } \\
\text { empresa }\end{array}$ & 31,25 & 6,25 & 31,25 & 12,50 & 18,75 \\
\hline $\begin{array}{l}\text { Os objetivos da empresa } \\
\text { são facilmente atingidos } \\
\text { sem o orçamento }\end{array}$ & 21,87 & 15,62 & 3,13 & 37,50 & 12,50 \\
\hline
\end{tabular}

Fonte: Dados da pesquisa, 2018.

Para 93,77 dos empreendedores, a principal razão para não utilizar o orçamento é a dificuldade para a sua implantação, em sequência a razão é a falta de conhecimento dos empreendedores. 


\section{CONSIDERAÇÕES FINAIS}

O estudo buscou identificar com os micros e pequenos empresários de Santos-SP se utilizam o orçamento empresarial no processo de gestão, envolvendo o planejamento, execução, controle e análise de desempenho. Em caso de os empreendedores não utilizar as práticas, procurou-se identificar as razões para isto.

A maioria utiliza o orçamento de curto prazo e é feita uma revisão no orçamento semestralmente por ele. As projeções mais utilizadas é o orçamento de vendas e demonstração do resultado do exercício.

As empresas que não fazem uso do orçamento, em sua maioria relata que tem dificuldade de implantação e falta de conhecimento na área para começar a utilizar a ferramenta.

Como sugestão para pesquisas futuras, sugere-se que seja ampliada a amostra, incluindo outras cidades de São Paulo ou até mais empreendedores de Santos, assim como cidades de outros estados brasileiros. E também acrescentar outras variáveis que possam estar relacionadas com a utilização do orçamento.

\section{REFERÊNCIAS}

Boas, A. V. \& Jones, G. D. C. (2005). Planejamento financeiro e controle orçamentário: Um estudo de caso em uma empresa industrial. Revista Contemporânea de Economia e Gestão, 3(1), p. 25-34.

Brinded, L. (2015) The 9 countries with the most entrepreneurship. Business Insider, UK. Recuperado em 14 abril, 2018, de http://uk.businessinsider.com/top-9-countries-with-thelargest-amount-of-entrepreneurs-2015-6?r=US/

Catelli, A. (2001). Controladoria: uma abordagem de gestão econômica - GECON. 2a . Ed. São Paulo: Atlas.

Carneiro, M. \& Matias, A. B. (2011). Orçamento empresarial: teoria, prática e novas técnicas. São Paulo: Atlas.

Correia Neto, J. F. (2011). Planejamento e controle orçamentário: manual de orçamento empresarial. Rio de Janeiro: Elsevier.

Fank, O. L., Angonese, R. \& Lavarda, C. E. F. (2011). A Percepção dos Gestores Acadêmicos de uma IES quanto às Críticas ao Orçamento. Contabilidade, Gestão e Governança, 14(1).

Fernandes, R. M. (2005). Orçamento empresarial - uma abordagem conceitual e metodológica com práticas através de simulador. Belo horizonte: Editora UFMG.

Frangiotti, A.T. (2010). Elaboração do orçamento empresarial com base na geração de valor. 2010. 126 f. Dissertação (Mestrado) - Faculdade de Economia, Administração e Contabilidade de Ribeirão Preto. Universidade de São Paulo, Ribeirão Preto, 2010. Recuperado em $\quad 05$ março, 2018, de http://www.teses.usp.br/teses/disponiveis/96/96132/tde-23112011-135821/pt-br.php

Gil, A. C. (2002). Como elaborar projetos de pesquisa. 4a. ed. São Paulo: Atlas.

IBGE. (2003). Instituto Brasileiro de Geografia e Estatística. As Micro e pequenas empresas comerciais e de serviços no Brasil: 2001. Rio de Janeiro. Recuperado de https://biblioteca.ibge.gov.br/visualizacao/livros/liv1898.pdf

Lopes, H. A., Blaschek, J. R. (2005). Orçamento empresarial: manter, aperfeiçoar ou abandonar?. Anais... Congresso Internacional de Custos, Florianópolis, SC, 9. Recuperado de https://anaiscbc.emnuvens.com.br/anais/article/viewFile/2100/2100 
Lunkes, R. J. (2010). Manual de orçamento. $2^{\mathrm{a}}$. ed. São Paulo: Atlas.

Martins, G. A., Theóphilo, C. R. (2009). Metodologia da Investigação Científica para Ciências Sociais Aplicadas. $2^{\mathrm{a}}$. ed. São Paulo: Atlas.

Oliveira, D. P. R. (2010). Planejamento estratégico: conceitos, metodologia e práticas. $28^{\mathrm{a}}$. ed. São Paulo: Atlas.

Oliveira, L. M., Perez Jr, J. H. \& Silva, C. A. S. (2009). Controladoria Estratégica. 5a. ed. São Paulo: Atlas.

Padoveze, C. L. (2010). Contabilidade Gerencial: um enfoque em sistema de informação contábil. $7^{\text {a }}$. ed. São Paulo: Atlas.

Padoveze, C. L. (2015). Planejamento Orçamentário. 3a. Ed. São Paulo: Cengage Learning.

Padoveze, C. L. \& Taranto, F. C. (2009). Orçamento empresarial: novos conceitos e técnicas. São Paulo: Pearson Education do Brasil.

Pontes, G. de A. (2013). Orçamento empresarial em pequenas empresas: Uma análise para o planejamento e controle de resultados. Revista Gestão Tecnologia e Ciência, 2(1), p. 2745.

Resnik, P. (1990). A Bíblia da pequena empresa: como iniciar com segurança sua pequena empresa e ser muito bem-sucedido. São Paulo: McGraw-Hull, MAKRON books.

Richardson, R. (2009). Pesquisa Social: métodos e técnicas. $3^{\mathrm{a}}$.ed. São Paulo: Atlas.

Sebrae. (2019). Serviço Brasileiro de Apoio às Micro e Pequenas Empresas. (2006). Guia básico sobre os pequenos negócios no Estado de São Paulo / [organizador Marco Aurélio Bedê]. (2a. ed.). São Paulo. Recuperado de http://www.sebrae.com.br/Sebrae/Portal\%20Sebrae/UFs/SP/Pesquisas/guia_basico_pequ eno negocio.pdf

Sebrae. (2019) Serviço Brasileiro de Apoio às Micro e Pequenas Empresas. (2014). Participação das micro e pequenas empresas na economia brasileira. Brasília/DF. Recuperado https://m.sebrae.com.br/Sebrae/Portal\%20Sebrae/Estudos\%20e\%20Pesquisas/Participaca o\%20das\%20micro\%20e\%20pequenas\%20empresas.pdf

Sebrae. (2019) Serviço Brasileiro de Apoio às Micro e Pequenas Empresas. (2014). Micro e pequenas empresas geram 27\% do PIB do Brasil. Recuperado de https://www.sebrae.com.br/sites/PortalSebrae/ufs/mt/noticias/micro-e-pequenasempresas-geram-27-do-pib-dobrasil,ad0fc70646467410VgnVCM2000003c74010aRCRD

Sebrae. (2019) Serviço Brasileiro de Apoio às Micro e Pequenas Empresas. (2016). Sobrevivência das empresas no Brasil. Brasília/DF. Recuperado de http://www.sebrae.com.br/Sebrae/Portal\%20Sebrae/Anexos/sobrevivencia-das-empresasno-brasil-relatorio-2016.pdf

Suave, R. (2013). Construção de um modelo para avaliação do nível de sofisticação na utilização de práticas de orçamento. Dissertação (Mestrado) - Universidade Federal de Santa Catarina - $\quad$ Florianópolis, SC. Recuperado de https://repositorio.ufsc.br/handle/123456789/122571 